\title{
Long-lasting anticryptosporidial activity of nitazoxanide in an immunosuppressed rat model
}

\author{
Xunde Li ${ }^{1}$, Philippe Brasseur ${ }^{1}$, Patrice Agnamey ${ }^{1}$, Denis Leméteil ${ }^{1}$, Loïc Favennec ${ }^{1}$, Jean-Jacques Ballet ${ }^{2}$ and \\ Jean-François Rossignol ${ }^{3}$
}

\author{
${ }^{1}$ Laboratoire de Parasitologie, Faculté de Médecine-Pharmacie, and ADEN, UPRES-EA 3234, 76138 Rouen, France; \\ ${ }^{2}$ Laboratoire d'Immunologie et Immunopathologie, CHU Clemenceau, 14033 Caen Cedex, France; \\ ${ }^{3}$ Department of Infectious and Tropical Diseases, London School of Hygiene \& Tropical Medicine, Keppel Street, London \\ WC1E 7HT, UK
}

Key words: Cryptosporidium parvum, nitazoxanide, immunosuppressed rat model

\begin{abstract}
Cryptosporidium parvum, Tyzzer, 1912 is identified as a common cause of diarrhoea in immunocompetent individuals. In immunocompromised, especially HIV-infected subjects, cryptosporidiosis causes severe chronic diarrhoea. In this study, nitazoxanide (NTZ) was compared for curative activity with sinefungin (SNF) and paromomycin (PRM) in immunosuppressed rats, a screening model for anticryptosporidial agents. NTZ at either $50 \mathrm{mg} / \mathrm{kg} / \mathrm{day}, 100 \mathrm{mg} / \mathrm{kg} / \mathrm{day}$ or $200 \mathrm{mg} / \mathrm{kg} / \mathrm{day}$ resulted in seven days in a dose-dependent inhibition of oocyst shedding similar to that obtained with SNF (10 mg/kg/day) and PRM (100 $\mathrm{mg} / \mathrm{kg}$ /day). Further discontinuation of SNF or PRM $100 \mathrm{mg} / \mathrm{kg} /$ day therapy resulted in early relapse of oocyst shedding which reached the pre-treatment levels in 2-4 days. In contrast, seven days after discontinuation of therapy, shedding inhibition was unchanged in NTZ-treated rats. Data prompt further assessment of the activity of NTZ on sequestered C. parvum.
\end{abstract}

Cryptosporidium parvum Tyzzer, 1912 infection is recognised as an important cause of diarrhoea in man. While in immunocompetent individuals, cryptosporidiosis may be responsible for mild and self-limiting diarrhoea, infection may be prolonged and life-threatening in immunocompromised individuals, especially in AIDS patients (Griffiths 1998). Among the numerous compounds tested for specific treatment of cryptosporidiosis, none has been found consistently efficient (Blagburn et al. 1998, Tzipori 1998). Nitazoxanide (NTZ, 2-acetolyloxy-N-5-nitro 2-thiazolyl benzamide), a nitrothiazole salicylilate derivative partially absorbed from the gastro-intestinal tract, was found active on bacteria such as Helicobacter pylori, Clostridium difficile, Bacteroides fragilis, and a broad spectrum of parasites such as the helminths Taenia saginata, Hymenolepis nana, Fasciola hepatica and protozoans such as Isospora belli, Entamoeba histolytica, Giardia lamblia and Enterocytozoon bieneusi (Rossignol and Maisonneuve 1984, Dubreuil et al. 1996, Doumbo et al. 1997, Mégraud et al. 1998, Rossignol et al. 1998a, Bicart-See et al. 2000, McVay and Rolfe 2000). In clinical studies conducted with NTZ in AIDS patients with cryptosporidiosis, NTZ treatment reduced the duration of diarrhoea and oocyst shedding (Rossignol et al. 1998b, Davis et al. 2000, Rossignol et al. 2001) The aim of the present study was to document in vivo activity of NTZ in an immunosuppressed rat cryptosporidiosis model, compared to sinefungin (SNF) and paromomycin (PRM), which were previously found effective (Brasseur et al. 1994, Verdon et al. 1995).

\section{MATERIALS AND METHODS}

A previously described immunosuppressed rat model was used in this study Brasseur et al. (1988). Briefly, male Sprague Dawley rats from SPF breeding (Janvier, Saint Berthevin, France) weighting 200-250 g and free of C. parvum oocysts in faeces before experiment were used. Immunosuppression of animals was obtained by a regimen of $25 \mathrm{mg}$ hydrocortisone acetate (Roussel, Paris, France) injected subcutaneously twice a week for 5 weeks before, and 3 weeks after challenge by $C$. parvum oocysts. Controls were immunosuppressed rats without challenge with $C$. parvum oocysts. Animals were fed a regular low protein (7\%) diet (white bread exclusively), and housed one per cage. Each cage was sterilized twice a week to avoid possible reinfections. Drinking bottles were heatsterilized every day. Cryptosporidium parvum oocysts were obtained from the faeces of a calf infected with an isolate of human origin maintained by serial passage in calves (a kind gift of Dr. Naciri, INRA, Nouzilly, France). Faeces were stored in a $2.5 \%(\mathrm{wt} / \mathrm{vol})$ solution of potassium dichromate at $4^{\circ} \mathrm{C}$ for less than 3 months before use and oocysts were purified using a sucrose density gradient $(\mathrm{d}=1.044$ and $\mathrm{d}=$ 1.088). Each rat was infected by oral gavage at day 0 with $10^{5}$ C. parvum oocysts. From day 7 to day 14 after infection, 3 groups of 20 rats were administered nitazoxanide (NTZ, Romark Laboratories, Tampa, Florida, USA) at doses of 50, 100 and $200 \mathrm{mg} / \mathrm{kg} /$ day, respectively. NTZ was diluted in 5\% (vol/vol) DMSO in distilled water and administered in 3 parts daily. A control group consisted of 20 rats receiving DMSO in distilled water without drug three times a day. During the same period, two groups of 4 rats were treated with 10 $\mathrm{mg} / \mathrm{kg} /$ day of sinefungin (SNF, kindly provided by Aventis, Vitry sur Seine, France) or $100 \mathrm{mg} / \mathrm{kg} /$ day paromomycin 
(PRM, kindly provided by Parke Davis, Courbevoie, France), respectively. (Leméteil et al. 1993, Brasseur et al. 1994).

Curative activities of NTZ, SNF and PRM were evaluated by measuring oocyst shedding. For each animal, faeces were collected at two days intervals between day 7 and day 21 postinfection, resuspended in a $10 \%(\mathrm{vol} / \mathrm{vol})$ formalin solution, and homogenized. Oocysts were counted by phase-contrast microscopy examination of smears prepared by mixing faeces suspensions with a carbolfuchsine solution (Heine 1982). Results were expressed as the mean oocyst number per 10 microscopic fields $(\times 400)$. Percentages of inhibition were calculated as : [ (mean number of oocysts shed in the control group) minus (mean number of oocysts shed in the treated group) : (mean number of oocysts shed in the control group)] $\times 100$. In addition, the number of oocyst-shedder rats was noted in each group at day 21 and expressed as the ratio: (number of shedder rats) : (total number of rats).

Since a correlation was previously established in this model between oocyst shedding and ileal infection, control histological examinations were performed in 3 rats from each group at the end of experiment (Brasseur et al. 1994). A portion of ileum was collected, fixed in a $10 \%(\mathrm{wt} / \mathrm{vol})$ formalin solution, embedded in paraffin and stained by haematoxylin-eosin. Developmental stages of $C$. parvum were counted in the epithelial cells of 10 ileal villi.

Statistical comparisons between groups were performed using the Chi-square test or the non-parametric Mann and Whitney test, depending on the distribution of data.

All experiments were performed in agreement with the standards for animal experimentation of the French Ministry of Agriculture.

\section{RESULTS AND DISCUSSION}

One day after treatment was initiated, NTZ at all doses exerted significant inhibition of oocyst excretion $(\mathrm{p}<0.05$, Fig. 1). From day 9 to day 21 after infection, NTZ inhibition $(25-70 \%)$ was dose-dependent $(p<$ 0.05 ) and peaked between days 13 and 21. Significant SNF and PRM inhibition was detected 1 and 2 days after initiation of therapy, respectively, and reached $90 \%$ at day 13 (Fig. 2). At all doses, NTZ inhibition was maintained for seven days (day 15 to day 21) after cessation of therapy on day 15 . In contrast, cessation of PRM or SNF resulted in relapse of oocyst shedding 3 days later and lack of inhibition at day 21. At day 21, rats from all groups shed oocysts (except one in the group receiving $200 \mathrm{mg} / \mathrm{kg} /$ day NTZ). Mean numbers of developmental stages per 10 villi were 22,17 and 10 (mean standard deviation: $11 \%$ of the mean value) in rats receiving 50,100 or $200 \mathrm{mg} / \mathrm{kg} /$ day NTZ respectively, and were correlated with oocyst shedding $(\mathrm{r}=$ $0.82, \mathrm{p}<0.01$ ). No histological alteration of mucosa was observed in NTZ-treated rats.

Data suggest that NTZ is efficient in reducing oocyst shedding in an immunosuppressed rat model of cryptosporidiosis, in which more than 30 agents have been previously tested with reproducible and consistent results (Leméteil et al. 1993). In contrast with SNF and

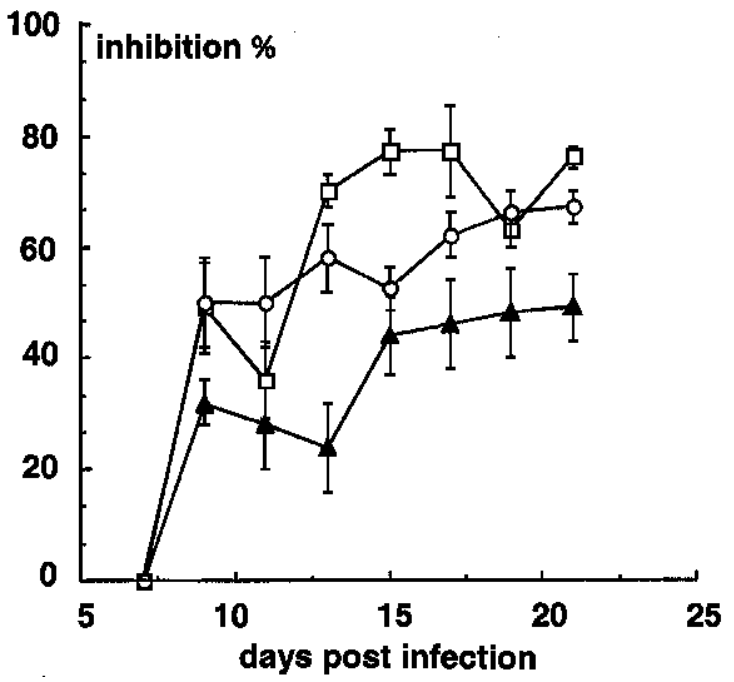

Fig. 1. Effects of nitazoxanide (NTZ) on Cryptosporidium parvum oocyst shedding in infected immunosuppressed rats. Results are expressed as mean $( \pm 1 \mathrm{SD})$ percentages of shedding inhibition compared to untreated controls.

$\boldsymbol{\Delta}$ - NTZ $50 \mathrm{mg} / \mathrm{kg} / \mathrm{day}, \mathrm{O}$ - NTZ $100 \mathrm{mg} / \mathrm{kg} /$ day, $\square$ - NTZ $200 \mathrm{mg} / \mathrm{kg} / \mathrm{day}$.

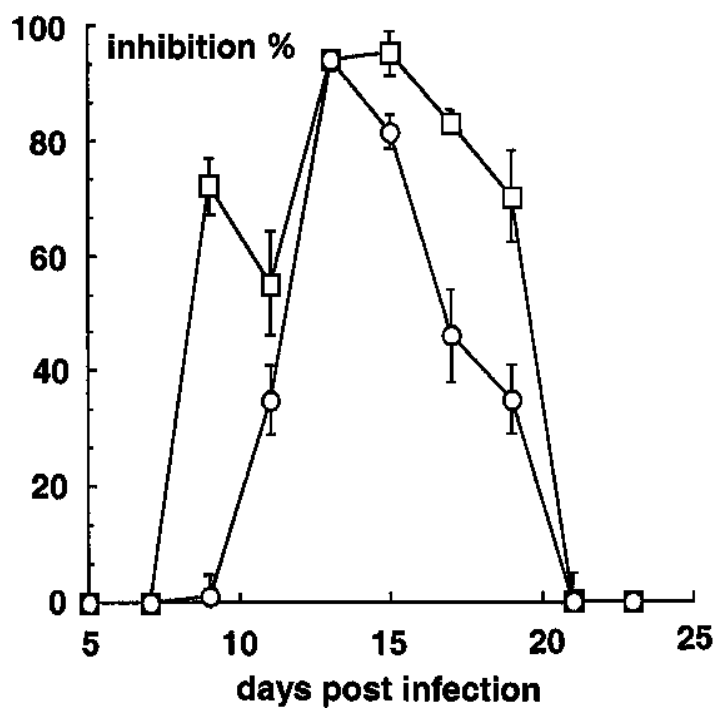

Fig. 2. Effects of sinefungin ( $\square-\mathrm{SNF}$ ) and paromomycin (O - PRM) on Cryptosporidium parvum oocyst shedding in infected immunosuppressed rats. SNF and PRM were given at doses of 10 and $100 \mathrm{mg} / \mathrm{kg} / \mathrm{day}$, respectively. Results are expressed as mean $( \pm 1 \mathrm{SD})$ percentages of shedding inhibition compared to untreated controls.

PRM, NTZ activity lasted at least 7 days after discontinuation of therapy. Both SNF and PRM were used as positive controls since their activities had been previously demonstrated in reducing oocyst shedding and parasite density in histological sections (Leméteil et al. 1993, Brasseur et al. 1994, Tzipori et al. 1994, Healey et al. 1995). NTZ has been previously tested in a 
number of different animal models with varying degrees of activity depending on the model used, the dose and the method of administration. In a gnotobiotic piglet model, 11-day treatment with $250 \mathrm{mg} / \mathrm{kg} / \mathrm{day}$ was effective in reducing oocyst shedding and mucosal infection (Theodos et al. 1998). However, using an antiIFN-gamma conditioned SCID mouse model, it was concluded that NTZ administered in $100 \%$ DMSO was ineffective in reducing oocyst shedding and mucosal infection, although partial reduction of oocyst shedding was noted in some experiments (Theodos et al. 1998). In a neonatal mouse model, oral administration of NTZ in $1 \%$ DMSO in distilled water, reduced oocyst output to less than 5\% (Blagburn et al. 1998). These discrepancies may be at least partially explained by differences in anti-cryptosporidial activities due to drug formulation. Fast absorption and elimination of NTZ administered in $100 \%$ DMSO may be responsible for lack of efficiency reported in a SCID mouse model, and using $5 \%$ DMSO may avoid some of the "clumping" of the chemical in the intestine (Blagburn et al. 1998, Theodos et al. 1998).

Although SNF and PRM were highly active during the period of treatment, oocyst shedding resumed after discontinuation of therapy. In contrast, in animals treated with NTZ, a dose-related oocyst shedding inhibition lasted at least 7 days after cessation of treatment. A likely explanation is that intestinal NTZ absorption results in metabolite concentrations active against $C$. parvum biliary sequestration, and data prompt further investigation of intestinal and extraintestinal anti-cryptosporidial activities of NTZ and/or its metabolites (Roussel et al. 1996).

Acknowledgements. This work was supported in part by a grant from the French Ministère de l'Aménagement du Territoire et de l'Environnement (1998). We thank Dr. Vuong, Hôpital Saint Michel, Paris, France for assistance in histological studies, and Junien Ballet and Michaëlina Hochet for their help in the preparation of the manuscript.

\section{REFERENCES}

BICART-SEE A., MASSIP P., LINAS M.D., DATRY A. 2000: Successful treatment with nitazoxanide of Enterocytozoon bieneusi microsporidiosis in a patient with AIDS. Antimicrob. Agents Chemother. 44: 167-168.

BLAGBURN B.L., DRAIN K.L., LAND T.M., KINARD R.G., MOORE P.H., LINDSAY D.S., PATRICK D.A., BOYKIN D.W., TIDWELL R.R. 1998: Comparative efficacy evaluation of dicationic carbazole compounds, nitazoxanide, and paromomycin against Cryptosporidium parvum infections in a neonatal mouse model. Antimicrob. Agents Chemother. 42: 2877-2882.

BLAGBURN B.L., SOAVE R. 1997: Prophylaxis and chemotherapy: human and animal. In: R. Fayer (Ed.), Cryptosporidium and Cryptosporidiosis. CRC Press, Boca Raton, pp. 111-128.

BRASSEUR P., FAVENNEC L., LEMÉTEIL D., ROUSSEL F., BALLET J.J. 1994: An immunosuppressed rat model for evaluation of anti-Cryptosporidium activity of sinefungin. Folia Parasitol. 41: 13-16.

BRASSEUR P., LEMÉTEIL D., BALLET J.J. 1988: Rat model for human cryptosporidiosis. J. Clin. Microbiol. 26: 1037-1039.

DAVIS L.J., SOAVE R., DUDLEY R.E., FESSEL J.W., FAULKNER S., MAMAKOS J.P. 2000: Nitazoxanide (NTZ) for AIDS-related cryptosporidial diarrhea (CD): an open-label safety, efficacy and pharmacokinetic study. In: Abstracts of the 36th Interscience Conference on Antimicrobial Agents and Chemotherapy. American Society for Microbiology, Washington, D.C., abstract LM50, p. 289.

DOUMBO O., ROSSIGNOL J.F., PICHARD E., TRAORE H.A., DEMBELE T.M., DIAKITE M., TRAORE F., DIALLO D.A. 1997: Nitazoxanide in treatment of cryptosporidial diarrhea and other intestinal parasitic infections associated with acquired immunodeficiency syndrome in tropical Africa. Am. J. Trop. Med. Hyg. 56: 637-639.
DUBREUIL L., HOUCKE I., MOUTON Y., ROSSIGNOL J.F. 1996: In vitro evaluation of activities of nitazoxanide and tizoxanide against anaerobes and aerobic organisms. Antimicrob. Agents Chemother. 40: 2260-2270.

GRIFFITHS J.L. 1998: Human cryptosporidiosis: epidemiology, transmission, clinical disease, treatment and diagnosis. Adv. Parasitol. 40: 37-85.

HEALEY M.C., YANG S., RASMUSSEN K.R., JACKSON M.K., DU C. 1995: Therapeutic efficacy of paromomycin in immunosuppressed adult mice infected with Cryptosporidium parvum. J. Parasitol. 81: 114-116.

HEINE J. 1982: Eine einfache Nachweismethode für Kryptosporidien im Kot. Zentralbl. Veterinaermed. 29: 324-327.

LEMÉTEIL D., ROUSSEL F., FAVENNEC L., BALLET J.J., BRASSEUR P. 1993: Assessment of candidate anticryptosporidial agents in an immunosuppressed rat model. J. Infect. Dis. 167: 766-768.

McVAY C.S., ROLFE R.D. 2000: In vitro and in vivo activities of nitazoxanide against Clostridium difficile. Antimicrob. Agents Chemother. 44: 2254-2258.

MÉGRAUD F., OCCHIALINI A., ROSSIGNOL J.F. 1998: Nitazoxanide, a potential drug to eradicate Helicobacter pylori with no cross resistance to metronidazole. Antimicrob. Agents Chemother. 42: 2836-2840.

ROSSIGNOL J.F., AYOUB A., AYERS M.S. 2001: Treatment of diarrhea caused by Cryptosporidium parvum: a prospective randomized, double-blind, placebo-controlled study of nitazoxanide. J. Infect. Dis. 184: 103-106.

ROSSIGNOL J.F., ABAZA H., FRIEDMAN H. 1998a: Successful treatment of human fascioliasis with nitazoxanide. Trans. R. Soc. Trop. Med. Hyg. 92: 103-104.

ROSSIGNOL J.F., HIDALGO H., FEREGRINO M., HIGUERA F., GOMEZ W.H., ROMERO J.L., PADIERNA J., GEYNE A., AYERS M.S. 1998b: A double-blind placebo-controlled study of nitazoxanide in the treatment of cryptosporidial diarrhoea in AIDS 
patients in Mexico. Trans. R. Soc. Trop. Med. Hyg. 92: 663-666.

ROSSIGNOL J.F., MAISONNEUVE H. 1984: Nitazoxanide in the treatment of Taenia saginata and Hymenolepis nana. Am. J. Trop. Med. Hyg. 33: 511-512.

ROUSSEL F., FAVENNEC L., LEMÉTEIL D., TAYOT J., BALLET J.J., BRASSEUR P. 1996: Biliary tract cryptosporidiosis in an immunosuppressed rat model. Int. J. Parasitol. 26: 19-24.

THEODOS C.M., GRIFFITHS J.K., D'ONFRO J., FAIRFIELD A., TZIPORI S. 1998: Efficacy of nitazoxanide against Cryptosporidium parvum in cell culture and in animal models. Antimicrob. Agents Chemother. 42: 1959-1965.

Received 10 June 2002
TZIPORI S. 1998: Cryptosporidiosis: laboratory investigation and chemotherapy. Adv. Parasitol. 40: 187-221.

TZIPORI S., RAND W., GRIFFITHS J., WIDMER G., CRABB J. 1994: Evaluation of an animal model system for cryptosporidiosis: therapeutic efficacy of paromomycin and hyperimmune bovine colostrum-immunoglobulin. Clin. Diagn. Lab. Immunol. 1: 450-463.

VERDON R., POLIANSKI J., GAUDEBOUT C., MARCHE C., GARRY L., CARBON C., POCIDALO J.J. 1995: Evaluation of high-dose regimen of paromomycin against cryptosporidiosis in the dexamethasone-treated rat model. Antimicrob. Agents Chemother. 39: 2155-2157.

Accepted 2 October 2002 